\title{
Preparation, Quality Control and Biodistribution Studies of two $\left[^{111}\right.$ In]-Rituximab Immunoconjugates
}

\section{Amir R. JALILIAN * ${ }^{1}$, Darush SARdarI ${ }^{2}$, Leila KIA ${ }^{2}$, Pejman Rowshanfarzad ${ }^{1}$, Javad Garousı ${ }^{1}$, Mehdi AKHLAGHI ${ }^{1}$, Saeed ShanehSAZzadeh ${ }^{1}$, Mohammad MIRZAII ${ }^{1}$}

${ }^{1}$ Nuclear Medicine Research Group, Agricultural, Medical and Industrial Research School (AMIRS), P.O.Box: 31485-498, Karaj, Iran.

${ }^{2}$ Islamic Azad University, Science and Research Unit, P.O.Box: 14155-775, Tehran, Iran.

\begin{abstract}
In order to use Auger-electron therapeutic effects in CD20 antigen targeting in lymphomas, Mabthera ${ }^{\mathrm{TM}}$ (rituximab) was successively labeled with $\left[{ }^{111} \mathrm{In}\right]$-indium chloride $(185 \mathrm{MBq})$ after conjugation with freshly prepared macrocyclic bifunctional chelating agent, $\quad N$-succinimidyl-1,4,7,10-tetraazacyclododecane-1,4,7,10-tetraacetic acid (DOTA-NHS) and ccDTPA separately. Conjugated-Rituximab was obtained by the addition of $1 \mathrm{ml}$ of a rituximab pharmaceutical solution $(5 \mathrm{mg} / \mathrm{ml}$, in phosphate buffer, $\mathrm{pH}=7.8$ ) to a glass tube pre-coated with freshly prepared DOTANHS or ccDTPA $(0.01-0.1 \mathrm{mg})$ at $25^{\circ} \mathrm{C}$. Radiolabeling was performed at $37^{\circ} \mathrm{C}$ in $3 \mathrm{~h}$ and room temperature for one hour for DOTA-conjugate and DTPA-conjugate respectively. HPLC showed an overall radiochemical purity of 97.5 and $95 \%$ for DOTA and DTPA-conjugates respectively (Specific activity $=2800-5600 \mathrm{GBq} / \mathrm{mM}$ ). The final isotonic ${ }^{111}$ In-rituximab complexes were checked by gel electrophoresis for radiolysis. Preliminary biodistribution studies in normal rat model performed to determine radioimmunoconjugates distribution of up to $48 \mathrm{~h}$.
\end{abstract}

* Corresponding author: Tel. ++98-261-4411101; Fax:++98-261-4411106.

E-mail: ajalilian@nrcam.org (A. R. Jalilian). 


\section{Keywords}

Rituximab • Indium-111 • Biodistribution • Radiolabeling • Targetted Therapy

\section{Introduction}

Several studies of radiolabeled anti-CD20 monoclonal antibodies at nonmyeloablative doses in treating B-cell $\mathrm{NHL}$ have been reported, and several are in progress. The agents for which most data are available are ${ }^{131}$ I-tositumomab (Bexxar) and yttrium ${ }^{90}$ Y-ibritumomab tiuxetan (Zevalin). These studies have reported response rates of $25 \%$ to $40 \%$ with median response duration of 6 to 18 months in most studies and some very durable responses of more than 5 years [14]. In some studies, rituximab has been labeled for metabolism and localization of CD20 antigens throughout the body and/or penetration of the antibody to specific organs [5].

In order to obtain an anti-CD20 conjugate for use in diagnostic/therapeutic studies, the ${ }^{111}$ In-labeled antibody was prepared as a model of metal chelated immunoconjugate for preliminary dosimetric and biodistribution studies in rats.

As bi-functional ligands, $N$-succinimidyl-1,4,7,10-tetraazacyclododecane1,4,7,10-tetraacetic acid (3, DOTA-NHS) [6] and freshly prepared ccDTPA were used.

DOTA ligand has already shown good biological performance when used in protein conjugation of various radioisotopes such as Ga-68 [7], Ga-66 [8], Ac-225 [9], Lu-177 [10] and lead radioisotopes [11].

Based on recent experiences on the preparation of radiometal-labeled rituximab for lymphoma imaging [12], we were interested in the preparation of an antiCD-20 immunoconjugate involving a cyclotron-produced radionuclide, i. e. In111 (HL:67 h, major photopeak at $172 \mathrm{keV}$ ).

A precise labeling strategy was employed using freshly-prepared DOTA-NHS and cCDTPA and optimized radiolabeling methods for developing highly reactive conjugated anti-CD20 for radiometal studies has been has been introduced for diagnosis and therapy purposes. 


\section{Results and discussion}

\section{Preparation and structure confirmation of DOTA NHS}

Various solvents can be used in the esterification reaction of DOTA and NHS, such as DMF, DMSO, etc. Due to the high boiling point of such solvents and the possibility of protein denaturing caused by these solvents, we tried to use dichloromethane based on the previous reports for DCC-mediated conjugation reactions [13]. This reaction is performed at room temperature and can be done overnight. Most of the reaction takes place in the first few hours. Considering the size exclusion chromatography performed in the next step of the process, all the starting materials can be separated. A more lipophillic species in the reaction mixture (monitored by TLC) is related to the formation of the ester. The exact stoichiometry of NHS:DOTA (1:1) is mandatory in order to avoid the formation of the di-succinimidyl ester.

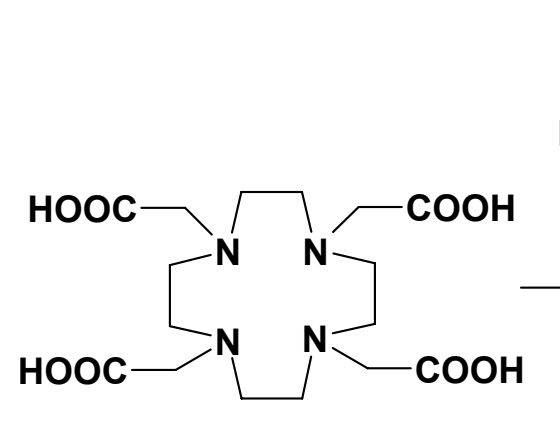

1

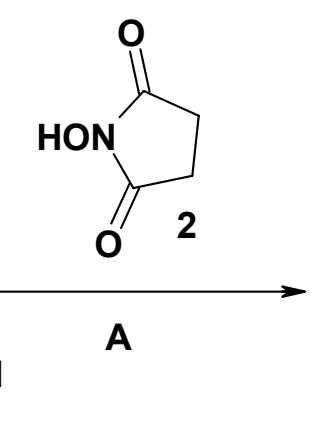

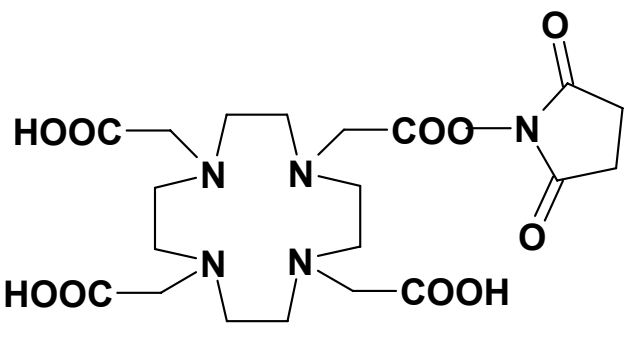

3

Fig. 1. Diagram of DOTA-NHS (3) synthesis. A: $\mathrm{CH}_{2} \mathrm{Cl}_{2}, 25^{\circ} \mathrm{C}, 15 \mathrm{~h}$

The formation of mono-succinimidyl ester at $R_{f}$ of 0.36 was observed. In case of longer reaction times another species at $R_{f}=0.56-0.6$ can be observed and is related to di-succinimidyl ester. All reactants remain at the $R_{f}$ of $0.0-0.1$.

Conjugation of rituximab with DOTA-NHS ester and radiolabeling of rituximab with ${ }^{111}$ In

The conjugated DOTA-rituximab fractions containing the maximum protein content were labeled with ${ }^{111} \mathrm{In}-\mathrm{InCl}_{3}$ solution. The samples were checked by RTLC 
to find the best time scale for labeling. After an hour, the free ${ }^{111} \mathrm{In} /$ conjugated ${ }^{111} \mathrm{In}$ ratio in the labeled sample remained unchanged at 2:98. The mixture could then be passed through another Sephadex G-50 size exclusion chromatography column in order to remove unbound ${ }^{111}$ In cation and/or other low molecular weight impurities.

The eluted fractions were checked by Folin-Colciteau ${ }^{\circledR}$ reagent and for the presence of radioactivity in order to determine the ${ }^{111}$ In-DOTA-rituximab containing fractions. Fraction with the highest radioactivity which contained the maximum color absorbance was chosen as the suitable final product with appropriate specific activity for animal tests. Instant thin layer chromatography using various mobile and stationary phases was performed in order to ensure the existence of only the desired radiolabeled antibody. Five different solvent systems and two stationary phases were tested. In all RTLC tests, radiolabeled antibody stayed at the origin while other species migrated to other $\mathrm{R}_{\mathrm{f}} \mathrm{s}$ depending on the mobile phase used. The $\mathrm{R}_{\mathrm{f}} \mathrm{S}$ of the possible occurring chemical species in chromatography of the reaction steps are summarized in Table $1(n=5)$. As shown in the table 1 , for $\ln ^{3+}$ detection the best eluent systems are system 5 and 6 resulting in $\mathrm{Rfs}$ of 0.8 and 0.9 respectively. For In-DOTA detection most of the systems used can demonstrate the amount of the component compared to the other fractions. However, systems 1-4 give very distinguishable Rfs in contrast to the others respectively $0.3,0.5,0.9$ and 0.9 . Due to the size and charge of the protein $(\approx 150,000 \mathrm{D}),{ }^{111}$ In-DOTA-rituximab remains at the origin in all systems used.

In HPLC studies using reverse phase column in 1mMDTPA as eluent. The fast eluting component (3.4 min) was shown to be a mixture of free ${ }^{111}$ In and ${ }^{111}$ InDTPA. Both compounds are ionic, so they are eluted at the same retention time. The radiolabeled protein was finally washed out at 15.86 minutes (Figure 2.).

Due to UV absorbance of DTPA moiety, the UV detector chromatogram can not be used for chemical purity determination, however using free DTPA and In-111 for control studies, it was shown that $98 \%$ of present DTPA at the reaction $\mathrm{pH}$ will form ${ }^{111}$ In-DTPA species which can be analyzed by flow scintillation analyzer. Assuming the only impurity in whole process would be DTPA. In the production 
Tab. 1. The $R_{f}$ values of chemical impurities and DOTA-conjugates

\begin{tabular}{|c|c|c|c|c|}
\hline & Chemical species & Mobile phase & $\begin{array}{c}\text { Stationary } \\
\text { phase }\end{array}$ & $\mathbf{R}_{\mathbf{f}}$ \\
\hline & ${ }^{111}$ In-DOTA-rituximab & $10 \% \mathrm{NH}_{4} \mathrm{OAc}: \mathrm{MeOH}(1: 1)$ & Silicagel & 0.0 \\
\hline 1 & ${ }^{111} \operatorname{In}^{3+}$ & // & // & 0.0 \\
\hline & ${ }^{111}$ In-DOTA & /I & /I & 0.3 \\
\hline \multirow{3}{*}{2} & ${ }^{111}$ In-DOTA-rituximab & Normal saline & /I & 0.0 \\
\hline & ${ }^{111} \ln ^{3+}$ & /I & /I & 0.1 \\
\hline & ${ }^{111}$ In-DOTA & // & // & 0.5 \\
\hline \multirow{3}{*}{3} & ${ }^{111}$ In-DOTA-rituximab & pyridine:ethanol: $\mathrm{H}_{2} \mathrm{O}(1: 2: 4)$ & // & 0.0 \\
\hline & ${ }^{111} \ln ^{3+}$ & // & // & 0.0 \\
\hline & ${ }^{111}$ In-DOTA & /I & // & 0.9 \\
\hline \multirow{3}{*}{4} & ${ }^{111}$ In-DOTA-rituximab & Methanol:ammonia (3:2) & // & 0.0 \\
\hline & ${ }^{111} \operatorname{In}^{3+}$ & // & // & 0.1 \\
\hline & ${ }^{111}$ In-DOTA & /I & /I & 0.9 \\
\hline \multirow{3}{*}{5} & ${ }^{111}$ In-DOTA-rituximab & Water:methanol (45:55) & Whatman 1. & 0.0 \\
\hline & ${ }^{111} \ln ^{3+}$ & /I & $/ /$ & 0.8 \\
\hline & ${ }^{111}$ In-DOTA & /I & // & 0.9 \\
\hline \multirow{3}{*}{6} & ${ }^{111}$ In-DOTA-rituximab & 10 mM DTPA (pH. 5) & /I & 0.0 \\
\hline & ${ }^{111} \ln ^{3+}$ & /I & /I & 0.9 \\
\hline & ${ }^{111}$ In-DOTA & // & // & 0.9 \\
\hline
\end{tabular}

step of DOTA(NHS)-MAb conjugate, the charge/size difference between DOTA(NHS)-MAb conjugate and unconjugated antibody is negligible with respect to 150000 Da molecular size, however the best specific activity can be obtained by the reaction of DOTA-NHS:antibody (3:1) molar ratio. 


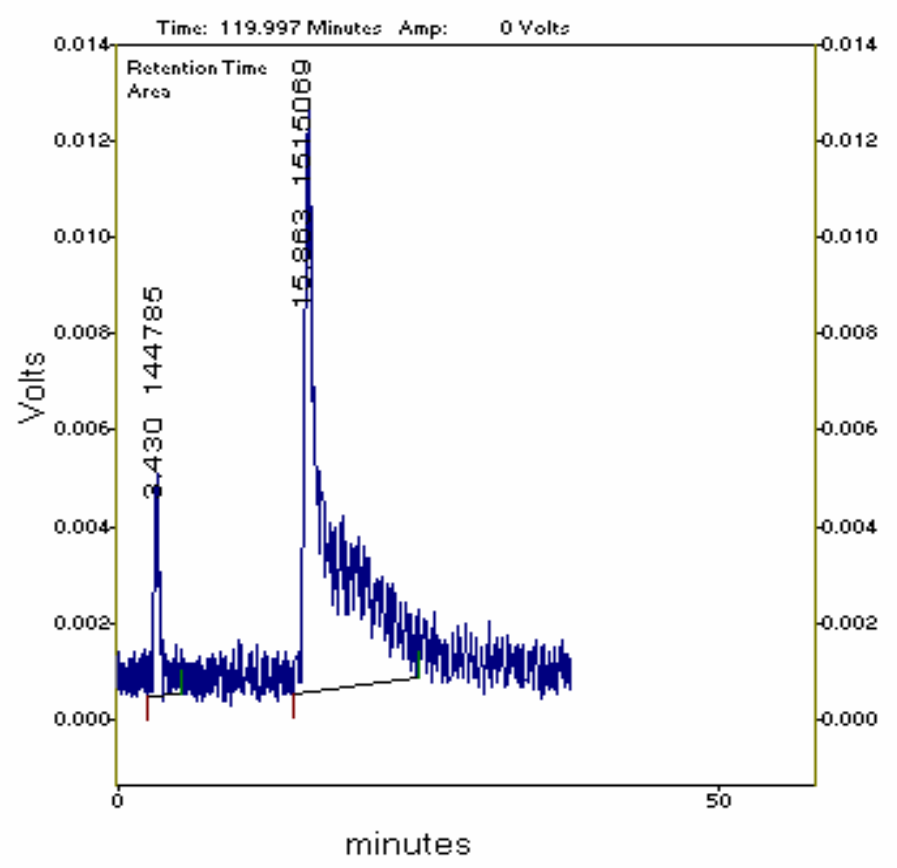

Fig. 2. HPLC chromatogram of final ${ }^{111}$ In-DTPA-rituximab solution on a reversed phase column using a gradient of acetate/citrate buffer

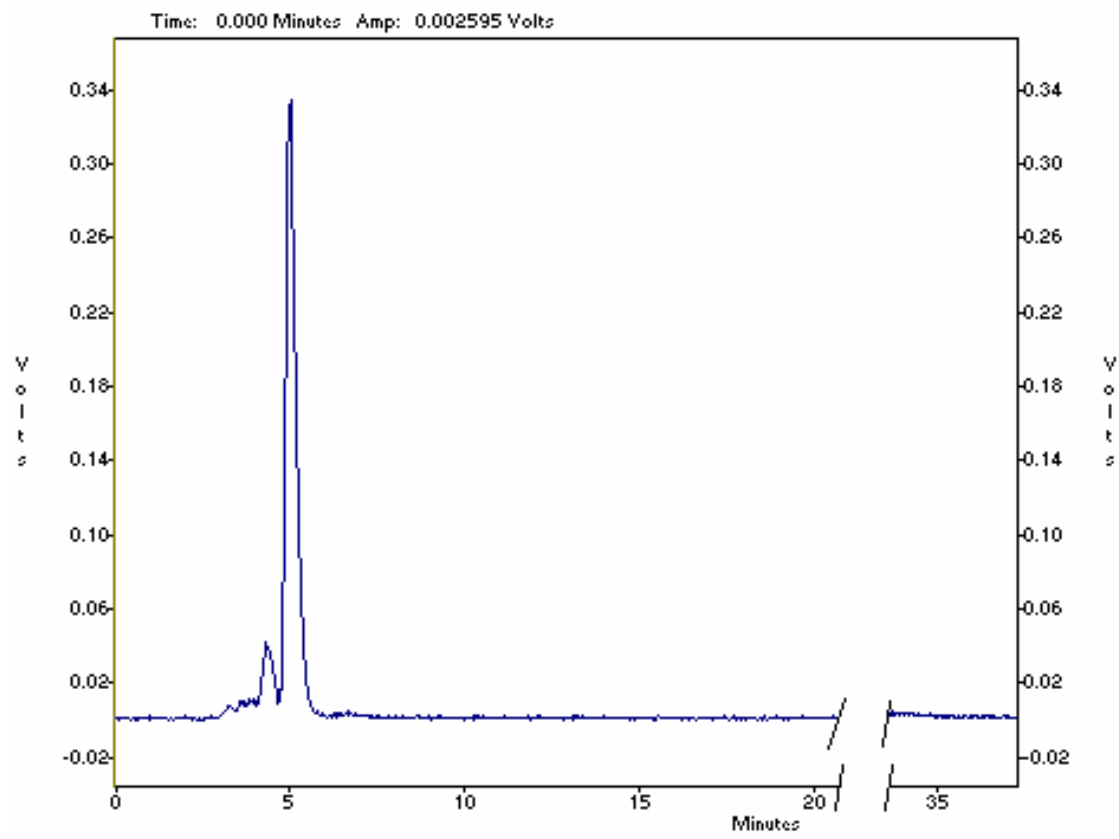

Fig. 3. HPLC chromatogram of final ${ }^{111}$ In-DOTA solution on a reversed phase column using a gradient of acetate/citrate buffer 


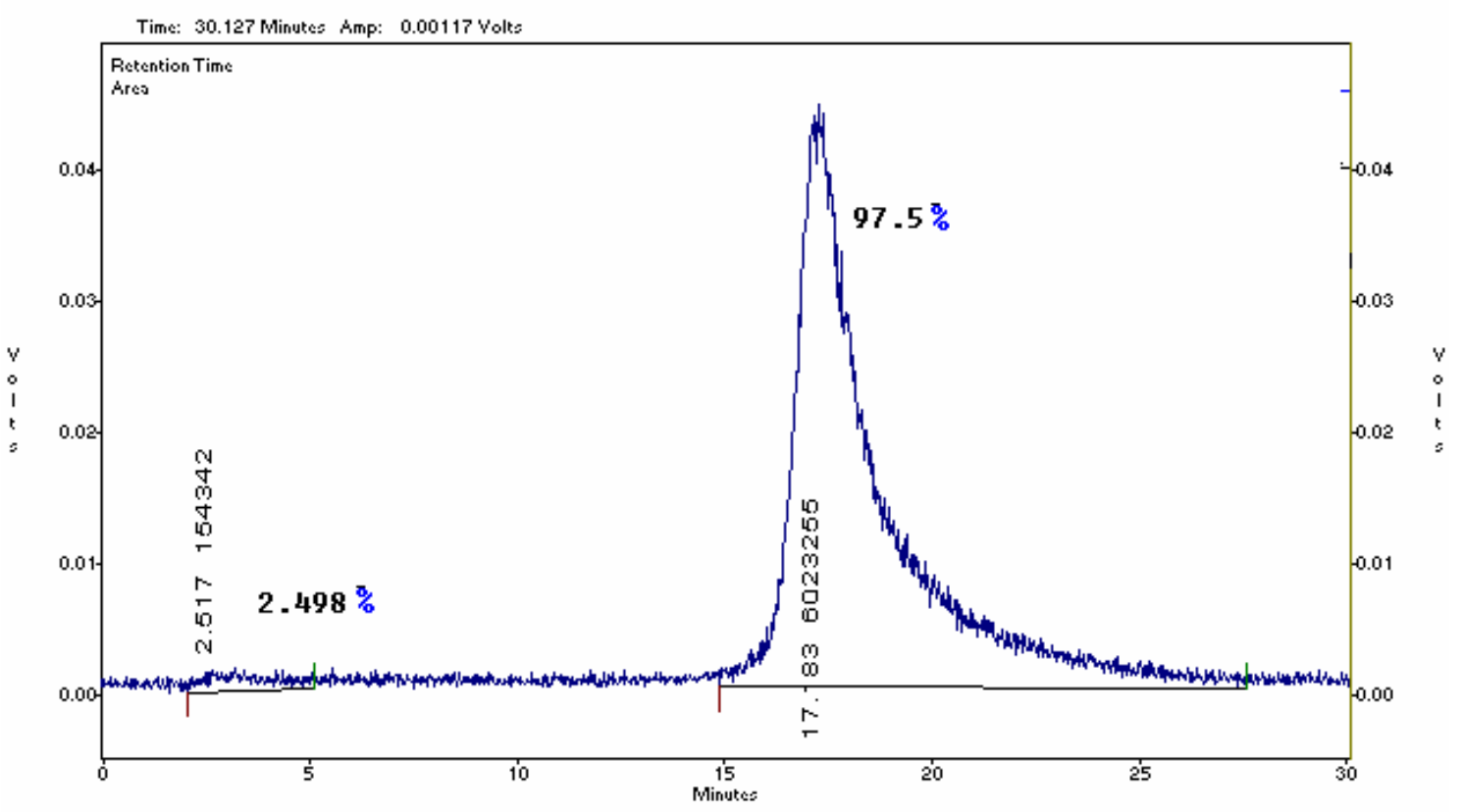

Fig. 4. HPLC chromatogram of final ${ }^{111}$ In-DOTA-rituximab solution on a reversed phase column using a gradient of acetate/citrate buffer

Since radiolabeling of each antibody molecule with one radioisotope atom at optimal theoretical conditions can be satisfactory, we chose the 1:1 molar ratio for the molar ratio. The only possible way to check the yield was RTLC/HPLC analysis of final radiolabeled antibody at various molar ratios (Figures 3,4 ).

\section{Stability of Radiolabeled Protein in presence of human serum in vitro}

After incubation of ${ }^{111}$ In-DOTA-rituximab with freshly prepared human serum at described conditions in the methods, $96-98 \%$ of the radioactivity eluted at the same fraction as ${ }^{111}$ In-DOTA-rituximab, using size exclusion chromatography. Thus, there was no evidence for either degradation or transchelation of ${ }^{111} \mathrm{In}$ to other serum proteins over a time period consistent with the normal blood clearance time of rituximab.

\section{Protein integrity test using SDS-Polyacrylamide Gel Electrophoresis}

In order to demonstrate the integrity of the protein after conjugation and radiolabeling gel electrophoresis was performed on the SDS PAGE gels using $16 \%$ bisacrylamide gel. The loaded samples were Rituximab commercial sample, DOTA- 
rituximab and radiolabeled protein samples a week after the experiment while kept in the fridge. The 3 samples were showed to have similar pattern of migration in the gel electrophoresis.

Interestingly the SDS PAGE results were checked with a reported commercial Rituximab sample [16]. Figure 5. shows the SDS-PAGE patterns for both DOTA and DTPA conjugates in contrast to starting Rituximab sample and radiolabeled immunoconjugates.

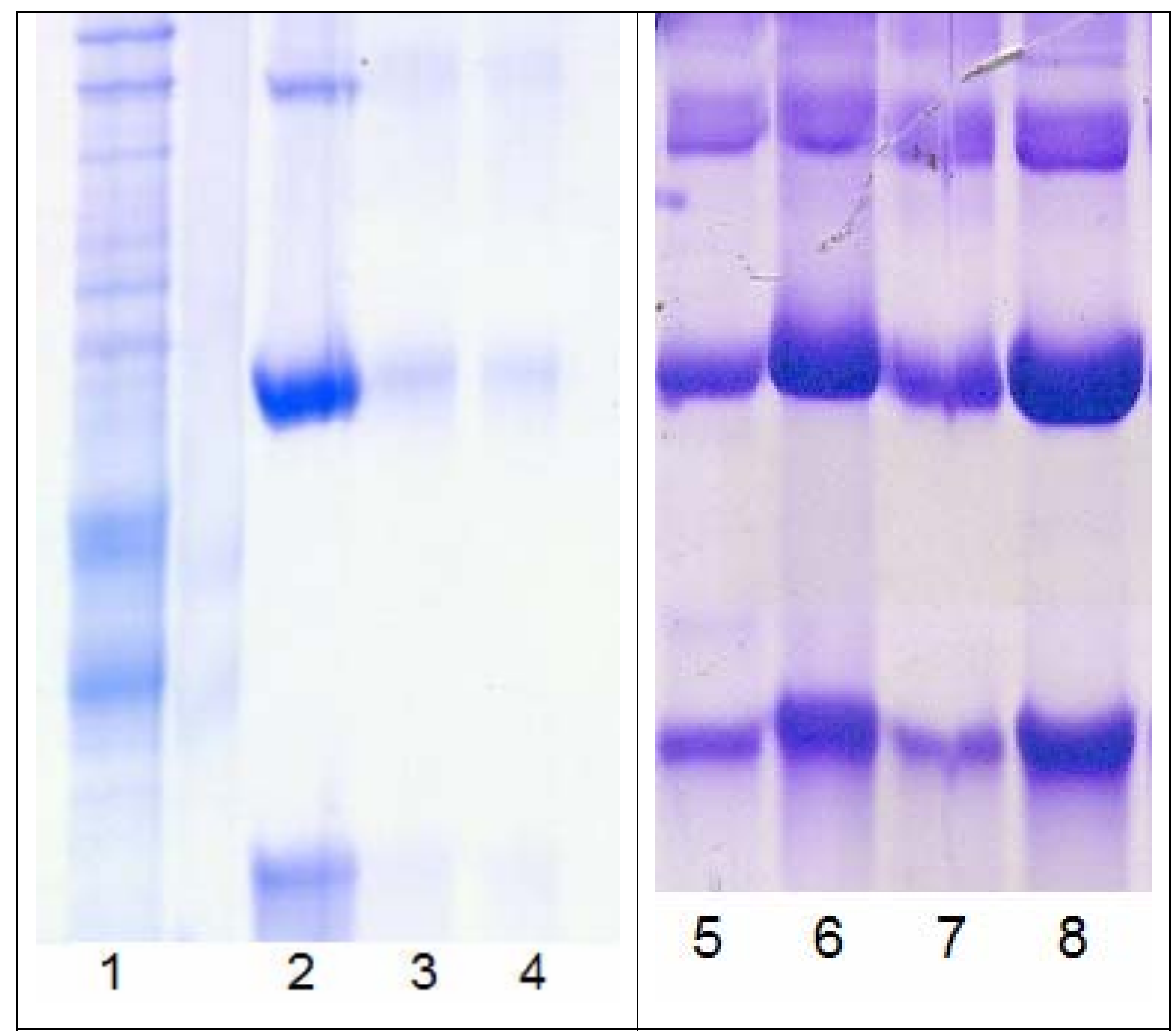

Fig. 5. SDS-PAGE lane patterns for Rituximab $(2,6,8)$, DOTA-rituximab conjugate (3) and ${ }^{111}$ In-DOTA-rituximab (4), DTPA-rituximab conjugate (5), ${ }^{111}$ In-DOTArituximab (7) in contrast to in house-made standard ladder (1).

\section{Biodistribution studies}

The animals were sacrificed by ether asphyxiation at selected times after injection (24, 48 and $72 \mathrm{~h}$ for DTPA conjugate and 2, 24 and $48 \mathrm{~h}$ for DOTA conjugate). Dissection began by drawing blood from the aorta, followed by collecting blood, heart, spleen, kidneys, liver, intestine, stomach, lung and skin 
samples. The tissue uptakes were calculated as the percent of area under the curve of the related photo peak per gram of tissue (\% ID/g) (Figures 6, 7).

At two hours post injection, the activity is mainly in the blood which is in agreement with the other reported labeled antibodies [14], while the activity of the stomach, muscle, intestine and spleen is rather low.

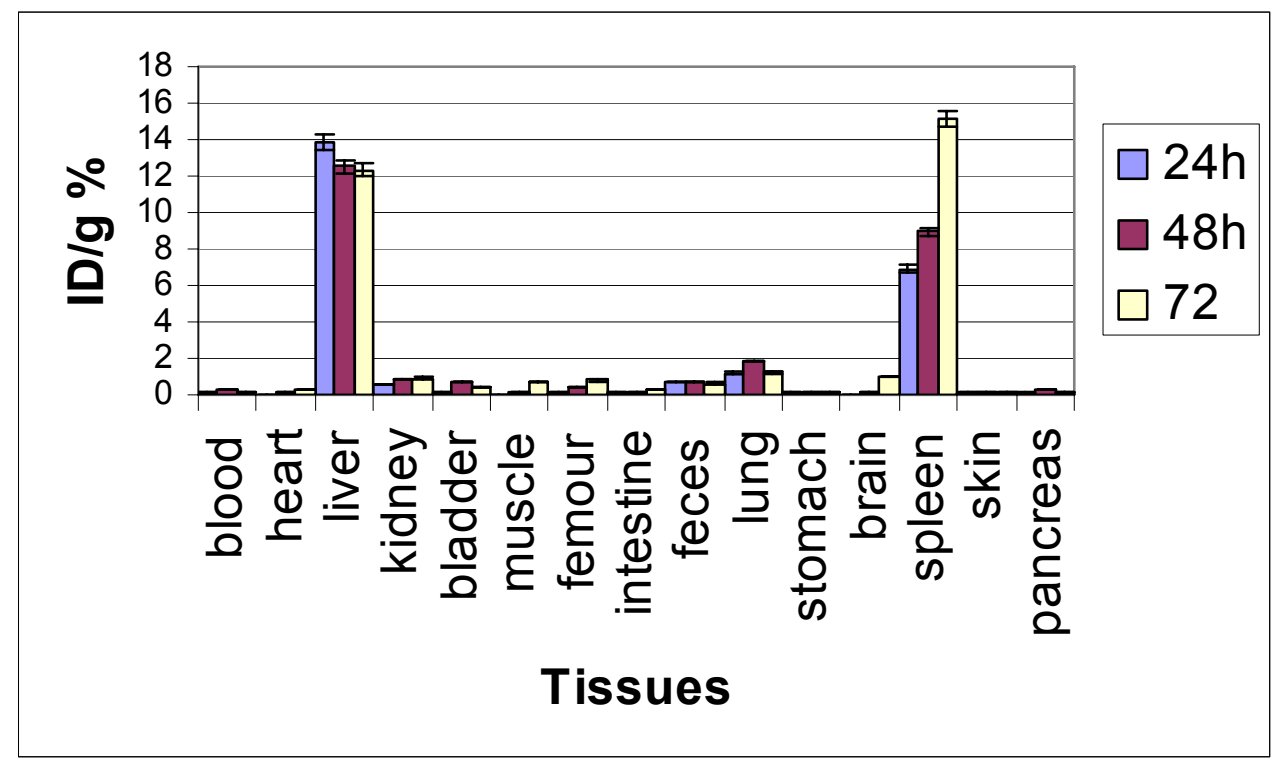

Fig. 6. Percentage of injected dose per gram (ID/g \%) of ${ }^{111}$ In-DTPA-rituximab in normal rat tissues at 24,48 and $72 \mathrm{~h}$ post injection

The brain did not show any significant uptake over the period of time. This had already been shown by ${ }^{123}$ I-antiCD20 conjugate biodistribution studies [5]. High uptake in spleen and reticuloendothelial organs was observed, which is due to the final accumulation of $B$ lymphocytes carrying the radioimmunoconjugate on their surface. The increasing uptake of spleen as a course of time is a direct result of the depletion of circulating $B$ cells occurring rapidly after administration to the mammals. This has been already shown in human, which is an important sign of therapy in lymphoma patients [15]. 


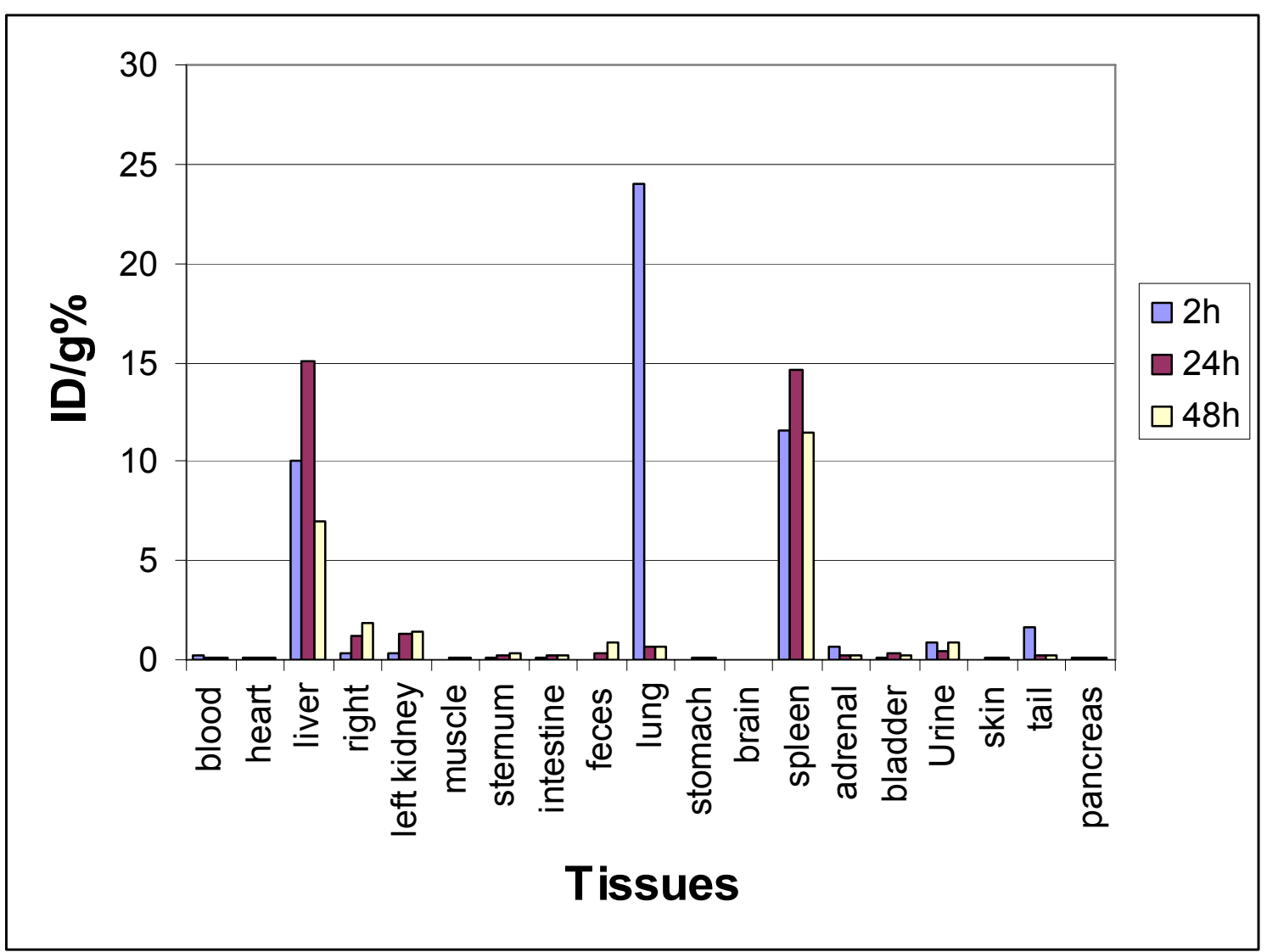

Fig. 7. Percentage of injected dose per gram (ID/g \%) of ${ }^{111}$ In-DOTA-rituximab in normal rat tissues at 2, 24 and $48 \mathrm{~h}$ post injection

As a natural reaction to the depletion of the lymphocytes the reticulloendothelial system including spleen will be the final possible reservoir of the depleted lymphocytes. However a direct resemblance of CD-20 antigen in human and rats has not been demonstrated. On the other hand, rituximab natural binding was found on lymphoid cells in the thymus, the white pulp of the spleen, and a majority of B-lymphocytes in peripheral blood and the lymph nodes in human being [16], this has been observed in our studies on the normal rats as well.

In some rats tested, accumulation in the lungs was observed. At the beginning it was concluded that this accumulation is caused by the non-specific immigration of the lymphocytes to the possibly infected bronchi of the objects which the infection. But the infection was not later confirmed by the lab tests post-mortem. Interestingly, we found reports of severe pulmonary reactions with pulmonary infiltrates or edema 
in human casued by anti-CD20. Acute symptoms appear within 1-2 hours of the initiation of the 1st infusion [17].

\section{Experimental}

Production of ${ }^{111}$ In was performed at the Agricultural, Medical and Industrial Research School (AMIRS), $30 \mathrm{MeV}$ cyclotron (Cyclone-30, IBA) using ${ }^{\text {nat }} \mathrm{Cd}(\mathrm{p}, \mathrm{x})^{111} \mathrm{In}$. Natural cadmium sulfate with purity of $>95 \%$ was obtained from Merck Co. Germany. Sephadex G-50, sodium acetate, phosphate buffer components, methanol and cyclic DTPA dianhydride were purchased from SigmaAldrich Chemical Co. U.K. NHS DOTA was freshly prepared and kept under a blanket of dry $\mathrm{N}_{2}$.

Rituximab was a pharmaceutical sample purchased from Roche Co. and was used without further purification. Radio-chromatography was performed by counting polymer-backed silica gel paper and/or $\mathrm{C}_{18}$ thin layer sheets using a thin layer chromatography scanner, Bioscan AR2000. Analytical HPLC to determine the specific activity was performed by a Shimadzu LC-10AT, armed with two detector systems, flow scintillation analyzer (Packard-150 TR) and UV-visible (Shimadzu) using Whatman Partisphere C-18 column $250 \times 4.6 \mathrm{~mm}$, Whatman Co. NJ, USA. Calculations were based on the $172 \mathrm{keV}$ peak for ${ }^{111} \mathrm{In}$. All values were expressed as mean \pm standard deviation (Mean \pm SD) and the data were compared using student T-test.

Statistical significance was defined as $P<0.05$. Animal studies were performed in accordance with the United Kingdom Biological Council's Guidelines on the Use of Living Animals in Scientific Investigations, 2nd edn.

\section{Production and quality control of ${ }^{111} \operatorname{In}-\mathrm{InCl}_{3}$ solution}

Cadmium electroplating over a copper surface was performed according to previously reported method [18]. ${ }^{111}$ In-indium chloride was prepared by $20 \mathrm{MeV}$ proton bombardment of the natural Cd target [13]. The presence of copper and cadmium impurities in the final solution was checked using acidic dithizone solution 
and alkaline dimethylglyoxime and NaK tartrate respectively according to the procedure $[19,20]$.

\section{Conjugation of cyclic DTPA di-anhydride with rituximab}

The chelator diethylenetriamine penta-acetic acid dianhydride was conjugated wth the Rituximab using a small modification of the well-known cyclic anhydride method [21]. Conjugation was performed at a 1:1 molar ratio. In brief, $20 \mu \mathrm{l}$ of a 1 $\mathrm{mg} \mathrm{ml}^{-1}$ suspension of DTPA anhydride in dry chloroform (Merck, Darmstadt, Germany) was pipetted under ultrasonication and transferred to a glass tube. The chloroform was evaporated under a gentle stream of nitrogen. Commercially available Rituximab (5 mg, $0.5 \mathrm{ml}, \mathrm{pH} 7.5$ ) was subsequently added and gently mixed at room temperature for $60 \mathrm{~min}$. Conjugation mixture was then passed through a Sephadex G-50 column $\left(2 \times 15 \mathrm{~cm}, 2 \mathrm{~g}\right.$ in $50 \mathrm{ml}$ of Milli- $\mathrm{Q}^{\circledR}$ water $)$ separately and one-milliliter fractions were collected and checked for the presence of protein using UV absorbance at $280 \mathrm{~nm}$ or visible folin-phenol colorimetric assay. The fractions containing the highest concentration of the immunoconjugate were chosen and kept at $4^{\circ} \mathrm{C}$ and for radiolabeling.

Preparation of N-succinimidyl-1,4,7,10-tetraazacyclododecane-1,4,7,10-tetraacetic acid (DOTA-NHS) (= 2,2',2"-(10-\{2-[(2,5-dioxopyrrolidin-1-yl)oxy]-2oxoethyl\}-1,4,7,10-tetraazacyclododecane-1,4,7-triyl)triacetic acid) for optimal protein conjugation

This compound was prepared according to methods previously given in the literature with slight modifications [22]. For a single run, a mixture of DOTA in acidic form (4 mg, $0.01 \mathrm{mmol}$ ), N-hydroxysuccinimide (1.15 mg, $0.01 \mathrm{mmol}$ ) and dicyclohexyl carbodiimide (DCC) $(2 \mathrm{mg}, 0.01 \mathrm{mmol})$ were dissolved in anhydrous $\mathrm{CH}_{2} \mathrm{Cl}_{2}(300-500 \mu \mathrm{l})$ under a blanket of $\mathrm{N}_{2}$ in a glass vial. The mixture was vortexed for $30 \mathrm{~s}$ and stirred at $25^{\circ} \mathrm{C}$ for $15 \mathrm{~h}$. Thin layer chromatography using ethyl acetate:hexane (1:1) mixture as mobile phase was performed in order to monitor the reaction progress. 


\section{Conjugation of NHS-DOTA with the rituximab}

The chelator $N$-succinimidyl-1,4,7,10-tetraazacyclododecane-1,4,7,10tetraacetic acid (DOTA-NHS) prepared above, was conjugated to the antibody using a small modification of the DOTA-NHS method [23]. The residue mixture above was evaporated under a flow of $\mathrm{N}_{2}$ gas in a glass tube producing a thin film coat of DOTA-NHS. The commercially available antibody Rituximab ${ }^{\circledR}(5 \mathrm{mg} / \mathrm{ml}$, $\mathrm{pH} .7 .8,0.5 \mathrm{ml}$ ) was added to the coated glass tube while gently mixed at room temperature for $30 \mathrm{~s}$. The mixture was then incubated in a water bath at $25^{\circ} \mathrm{C}$ for 15-18 hours.

This conjugation mixture was then passed through a Sephadex G-50 column ( $2 \times 15 \mathrm{~cm}$, prepared by soaking $2 \mathrm{~g}$ of the resin in $50 \mathrm{ml}$ of Milli- $\mathrm{Q}^{\circledR}$ water overnight) separately and one-milliliter fractions were collected and checked for the presence of protein using UV absorbance at $280 \mathrm{~nm}$ or visible folin-phenol colorimetric assay. The fraction containing the highest concentration of the immunoconjugate was chosen and kept at $4^{\circ} \mathrm{C}$ and for radiolabeling.

\section{Radiolabeling of the antibody conjugate with ${ }^{111}$ In}

The antibody conjugate was labeled using an optimization protocol according to the literature [24]. Typically, $40-400 \mathrm{MBq}$ of ${ }^{111}$ In-chloride (in $0.2 \mathrm{M} \mathrm{HCl}$ ) was added to a conical vial and dried under a flow of nitrogen. To the In-containing vial was added acetate buffer $(200 \mu \mathrm{l}, \mathrm{pH} .4 .8)$ and the vial vortexed for 30 seconds. The protein containing fraction with the maximum protein content was added in $1 \mathrm{ml}$ of phosphate buffer $(0.1 \mathrm{M}, \mathrm{pH}=8)$ to the vial and mixed gently for 30 seconds. The resulting solution was incubated at $37^{\circ} \mathrm{C}$ for $2-3$ hours. Following incubation, the radiolabeled antibody conjugate was purified from free ${ }^{111}$ In by size exclusion chromatography on a Sephadex G-50 column (15-20 ml bed volume) and eluted with PBS. Fractions $(1 \mathrm{ml})$ were collected and the radioactivity of each fraction was measured by a recently calibrated radioisotope dose calibrator (CRC-7, Capintec Instruments, Ramsey, $\mathrm{NJ}$ ). The protein presence in each fraction was determined using a fast protein assay method by mixing freshly prepared Folin-Colciteau ${ }^{\circledR}$ 
reagent ( $5 \mu$ l prepared by mixing $25 \mu$ l of fresh CuTartrate solution) and $10 \mu$ l of the eluted fractions. The fractions containing the proteins (visible blue color by naked eye) with the maximum radioactivity was tested for purity by ITLC using a radio TLC scanner. Control labeling experiments were also performed using ${ }^{111} \mathrm{InCl}_{3}$, and DOTA with ${ }^{111} \mathrm{InCl}_{3}$. Both reaction mixtures were passed through separate size exclusion chromatography columns and eluted with PBS. The fraction number 5-7 showed the presence of protein, which fraction 6 was used in the other experiments $(n=3)$.

\section{Preparation of ${ }^{111}$ In-DOTA for control studies}

For control studies, ${ }^{111}$ In-DOTA was prepared for $R_{f}$ and retention time studies in chromatographic methods [19]. For preparation, $37 \mathrm{MBq}$ of ${ }^{111}$ In-chloride (in $0.2 \mathrm{M}$ $\mathrm{HCl}$ ) was added to a conical vial and dried under a flow of nitrogen. To the Incontaining vial were added phosphate buffer $(0.1 \mathrm{M}, 200 \mu \mathrm{l}, \mathrm{pH} .8)$ and the vial vortexed for 30 seconds (final pH. 7.5). A solution of DOTA (1 mg, $2.5 \mathrm{mM}$ ) in 300 $\mu \mathrm{l}$ of phosphate buffer $(0.1 \mathrm{M}, \mathrm{pH}=8)$ was added to the first vial and mixed gently for 30 seconds. The resulting solution was incubated at $37^{\circ} \mathrm{C}$ for 3 hours.

\section{Quality control of ${ }^{111}$ In-DOTA-rituximab}

\section{Thin layer chromatography}

System I: A $5 \mu$ sample of the final fraction was spotted on a silica gel paper and developed in a mixture of $10 \%$ ammonium acetate:methanol $(1: 1)$ as the mobile phase, in order to observe the Rfs of free ${ }^{111} \ln ^{3+}$ and ${ }^{111} \operatorname{In}$-DOTA. Both $\ln ^{3+}$ and radiolabeled protein stay at $\mathrm{R}_{\mathrm{f}}=0.0$ [17].

System II: From the final product, $5 \mu \mathrm{l}$ was applied to a silica-impregnated glass fiber sheet followed by developing in $0.9 \% \mathrm{NaCl}$ for $5 \mathrm{~min}$. Radioactivity was determined by a chromatography scanner equipped with an HPGe crystal. ${ }^{111}$ InDOTA will move to the front, the ${ }^{111}$ In-labelled monoclonal antibody remains at the starting position [9].

System III: Another system was performed on silica-impregnated glass fibre sheets. From the final product, $5 \mu \mathrm{l}$ was applied to the ITLC strip that was 
developed with a mixture of pyridine:ethanol:water (1:2:4) for 5 min. Radioactivity was determined by a chromatography scanner equipped with an HPGe crystal. ${ }^{111}$ In-DOTA will move to the front, the ${ }^{111}$ In-labelled monoclonal antibody remains at the starting position [18].

\section{Paper chromatography}

Paper chromatography [Whatman No. 1 (Whatman, Maidstone, UK), methanol/water (55:45)] of the eluate showed that $>94 \%$ of the activity remained at the origin corresponding to the ${ }^{111}$ In-DOTA-conjugate. The labeling yield was $45 \pm 5 \%(n=3)$, and a specific activity of 300-500 Bq per 1 mg DOTA-conjugate was obtained [15].

\section{High performance liquid chromatography}

HPLC was performed on the final preparation using acetate buffer solution (50 $\mathrm{mM} \mathrm{pH}$. 5.5) as eluent (flow rate: $1 \mathrm{ml} / \mathrm{min}$ pressure: $130 \mathrm{KgF} / \mathrm{cm}^{2}$ ) for $20 \mathrm{~min}$ in order to elute low molecular weight components.

Radiolabeled antibody was eluted using a gradient of the latter solution (100 to $0 \%$ ) and citrate buffer solution ( $50 \mathrm{mM}, \mathrm{pH} .4,0$ to $100 \%)$ using reverse stationary phase. Any remaining free ${\operatorname{~}{ }^{3+}}^{3}$ cation can be complexed with citrate anion; however pre-complexed In-DTPA-rituximab was not challenged with the addition of citrate chelate [25].

\section{SDS-Polyacrylamide Gel Electrophoresis}

The radioimmunoconjugates were analyzed for integrity by SDSpolyacrylamide gel electrophoresis (SDS-PAGE). The radiolabeled mAb was evaluated with and without reduction by 2-mercaptoethanol. Approximately 200,000 cpm of each preparation was applied per lane and the $4-20 \%$ polyacrylamide were run according to the method of Laemmli [26].

\section{Stability testing of the radiolabeled compound in final formulation}

Stability of ${ }^{111}$ In-DOTA-rituximab in PBS was determined by storing the final solution at $4^{\circ} \mathrm{C}$ for 14 days and performing frequent ITLC analysis to determine 
radiochemical purity. The stability of the conjugated DOTA-rituximab stored at -20 ${ }^{\circ} \mathrm{C}$ for more than 3 months was also investigated. ITLC analysis of the conjugated product was performed to monitor for degradation products or other impurities. After subsequent ${ }^{111}$ In-labeling of the stored conjugated product, both labeling efficiency and radiochemical purity were determined.

\section{Stability testing of the radiolabeled compound in presence of human serum}

Radiolabel stability was assessed by size exclusion chromatography on a Sepharose column $(1 \times 30 \mathrm{~cm})$. The column was equilibrated with PBS and eluted at a flow rate of $0.5 \mathrm{~mL} / \mathrm{min}$ at room temperature; $1 \mathrm{~mL}$ fractions were collected.

\section{Biodistribution of ${ }^{111}$ In-radioimmunoconjugates to normal rats}

To determine its biodistribution, ${ }^{111}$ In-DOTA/DTPA-rituximab was administered to normal rats. A volume $(50-100 \mu \mathrm{l})$ of final ${ }^{111}$ In-DOTA/DTPA-rituximab solution containing $20 \pm 5 \mu \mathrm{Ci}$ radioactivity was injected intravenously to rats through their tail vein. The animals were sacrificed at the exact time intervals $(2-48 \mathrm{~h})$, and the specific activity of different organs was calculated as percentage of injected dose per gram using a radiometer.

\section{Conclusion}

Two separate rituximab conjugates were prepared and their behaviour in radiolabeling, quality control radiochemical purity were compared. For control studies ${ }^{111}$ In-DOTA was prepared and was checked using RTLC and HPLC. Total labeling, formulation and quality control of $\left[{ }^{111}\right.$ In]-DOTA-rituximab took about 3 hours, with a yield of $97.5 \%$ while using the optimized conditions. For $\left[{ }^{111} \operatorname{In}\right]$-DTPArituximab the chepurity was $95 \%$ and the labeling and quality control took one hour. The radio-labeled complexes were stable in human serum for at least 24 hours and no significant amount of free ${ }^{111}$ In as well as ${ }^{111}$ In-DOTA was observed. The final preparations were administered to normal rats and biodistribution of the radiopharmaceutical was checked $2-48$ hours later. $\left[{ }^{111}\right.$ In]-rituximab is potentially a good probe for diagnosis and therapy of lymphomas. Using the DOTA conjugate 
the incorporation of other therapeutic nuclides such as lanthanides and yttrium can be performed.

\section{Acknowledgements}

The authors wish to thank Mr A. Rajamand for providing Ga-67 and Mr Y. Yari Kamrani and Mr S. Daneshvari for conducting animal studies and finally $\mathrm{Mr} \mathrm{M}$. Naserian for SDSPAGE experiments. We acknowledge the financial support of the IAEO (4/2/1/9).

\section{References}

[1] Witzig TE, White CA, Wiseman GA, Gordon LI, Emmanouilides C, Raubitschek A, Janakiraman N, Gutheil J, Schilder RJ, Spies S, Silverman DH, Parker E, Grillo-Lopez AJ.

Phase I/II trial of IDEC-Y2B8 radioimmunotherapy for treatment of relapsed or refractory CD20(+) B-cell non-Hodgkin's lymphoma.

J Clin Oncol.1999; 17: 3793-3803.

[2] Eary JF, Press OW, Badger CC, Durack LD, Richter DK, Addison SJ, Krohn KA, Fisher DR, Porter BA, Williams DL. Imaging and treatment of B-cell lymphoma.

J Nucl Med. 1990; 31: 1257-1268.

[3] Knox SJ, Levy R, Miller RA, Uhland W, Schiele J, Ruehl W, Finston R, DayLollini R, Goris ML.

Determinants of the antitumor effect of radiolabeled monoclonal antibodies. Cancer Res. 1990; 50: 4935-4940.

[4] Kyle RA, Gertz MA, Greipp PR, Witzig TE, Lust JA, Lacy MQ, Therneau TM. Long-term survival (10 years or more) in 30 patients with primary amyloidosis.

Blood. 1999; 93: 1062-1066.

[5] Dietlein M, Pels H, Schulz H, Staak O, Borchmann P, Schomäcker K, Fischer T, Eschner T, Pogge von Strandmann E, Schicha H, Engert A, Schnell R. Imaging of central nervous system lymphomas with iodine-123 labeled rituximab.

Eur J Haematol. 2005; 74: 348-352.

[doi:10.1111/j.1600-0609.2004.00401.x] 
[6] Chappell LL, Ma D, Milenic DE, Garmestani K, Venditto V, Beitzel MP, Brechbiel MW.

Synthesis and evaluation of novel bifunctional chelating agents based on 1,4,7,10-tetraazacyclododecane-N,N',N",N"'-tetraacetic acid for radiolabeling proteins.

Nucl Med Biol. 2003; 30: 581-595.

[doi:10.1016/S0969-8051(03)00033-7]

[7] Hoffend J, Mier W, Schuhmacher J, Schmidt K, Dimitrakopoulou-Strauss A, Strauss LG, Kinscherf ERM, Haberkorna U.

Gallium-68-DOTA-albumin as a PET blood-pool marker: experimental evaluation in vivo.

Nucl Med Biol. 2005; 32: 287-292.

[doi:10.1016/j.nucmedbio.2005.01.002]

[8] Ugur O, Kothari PJ, Finn RD, Zanzonico P, Ruan S, Guenther I, Maecke HR, Larson SM.

Ga-66 labeled somatostatin analogue DOTA-DPhe1-Tyr3-octreotide as a potential agent for positron emission tomography imaging and receptor mediated internal radiotherapy of somatostatin receptor positive tumors.

Nucl Med Biol. 2002; 29: 147-157.

[doi:10.1016/S0969-8051(01)00290-6]

[9] McDevitt MR, Ma D, Simon J, Frank K, Scheinberg DA.

Design and synthesis of 225Ac radioimmunopharmaceuticals.

Appl Radiat Isot. 2002; 57: 841-847.

[doi:10.1016/S0969-8043(02)00167-7]

[10] Smith CJ, Galib H, Sieckmanc GL, Hayes DL, Owen NK, Mazuru DJ, Volkert WA, Hoffman TJ.

Gastrin releasing peptide (GRP) receptor targeted radiopharmaceuticals: a concise update.

Nucl Med Biol. 2003; 30: 101-109.

[doi:10.1016/S0969-8051(02)00391-8]

[11] Chappell LL, Dadachova E, Milenic DE, Garmestani K, Wu C, Brechbiel MW. Synthesis, characterization, and evaluation of a novel bifunctional chelating agent for the lead isotopes $203 \mathrm{~Pb}$ and $212 \mathrm{~Pb}$.

Nucl Med Biol. 2000; 27: 93-100.

[doi:10.1016/S0969-8051(99)00086-4]

[12] Gmeiner Stopar T, Mlinaric-Rascan I, Fettich J, Hojker S, Mather SJ. $(99 \mathrm{~m})$ Tc-rituximab radiolabelled by photo-activation: a new non-Hodgkin's lymphoma imaging agent.

Eur J Nucl Med Mol Imaging 2006; 33: 53-59.

[doi:10.1007/s00259-005-1838-4] 
[13] Lang L, Eckelman WC.

One-step synthesis of $18 \mathrm{~F}$ labeled [18F]-N-succinimidyl 4(fluoromethyl)benzoate for protein labeling.

Appl Radiat Isot. 1994; 45: 1155-1163.

[doi:10.1016/0969-8043(94)90031-0]

[14] Smith-Jones P, Solit DB, Akhurst T, Afroze F, Rosen M, Larsen SM. Imaging the pharmacodynamics of HER2 degradation in response to Hsp90 inhibitors

Nature Biotechnology. 2004; 22: 701-706.

[doi:10.1038/nbt968]

[15] http://www.pathologyoutlines.com/lymphoma.html

[16] Press OW, Leonard JP, Coiffier B, Levy R, Timmerman J. Immunotherapy of Non-Hodgkin's lymphomas.

Hematology Am Soc Hematol Educ Program. 2001; 221-240.

[17] Rituxan ${ }^{\circledR}$ (Roche) pamphlet, P.1, chapter B. CCO Formulary, Revised 2004/2005.

[18] Sadeghpour H, Jalilian AR, Akhlaghi M, Kamali-dehghan M, Mirzaii M. Preparation and Biodistribution of [111/n]-rHuEpo for Erythropoietin Receptor Imaging.

J Radioanal Nucl Chem. 2008; 278: 117-122.

[doi:10.1007/s1096700772121]

[19] Marczenko Z.

In: Spectrophotometric determination of elements.

New York: John Wiley \& Sons, 1976: 238-240.

[20] Marczenko Z.

In: Spectrophotometric determination of elements.

New York: John Wiley \& Sons, 1976: 176-179.

[21] Hnatowich DJ, Layne WW, Child RL, Lanteigne D, Davis MA, Griffin TW, Doherty PW.

Radioactive labeling of antibody: a simple and efficient method.

Science. 1983; 220: 613-619.

[doi:10.1126/science.6836304]

[22] Banerjee S, Das T, Chakraborty S, Samuel G, Korde A, Srivastava S, Venkatesha M, Pillai MRA.

177Lu-DOTA-lanreotide: a novel tracer as a targeted agent for tumor therapy.

Nucl Med Biol. 2004; 31: 753-759.

[doi:10.1016/j.nucmedbio.2004.04.002] 
[23] Mier W, Hoffend J, Kramer S, Schuhmacher J, Hull WE, Eisenhut M. Conjugation of DOTA using isolated phenolic active esters: the labeling and biodistribution of albumin as blood pool marker.

Bioconjug Chem. 2005; 16: 237-240.

[doi:10.1021/bc034216c]

[24] Pandey U, Mukherjee A, Sarma HD, Das T, Pillai MRA, Venkatesha M. Evaluation of 90Y-DTPA and 90Y-DOTA for potential application in intravascular radionuclide therapy.

Applied Radiat Isotopes. 2002; 57: 313-318.

[doi:10.1016/S0969-8043(02)00103-3]

[25] Green MA, Welch MJ.

Gallium radiopharmaceutical chemistry.

Int J Rad Appl Instrum B. 1989; 16: 435-448.

[26] Laemmli UK.

Cleavage of structural proteins during the assembly of the head of bacteriophage T4.

Nature (London) 1970; 227: 680-685.

[doi:10.1038/227680a0] 